Article

\title{
Thrust Force Ripple Reduction of Two C-Core Linear Flux-Switching Permanent Magnet Machines of High Thrust Force Capability
}

\author{
Wenjuan Hao ${ }^{1,2, *}$ and Yu Wang ${ }^{2}$ \\ 1 College of Jincheng, Nanjing University of Aeronautics and Astronautics, Nanjing 211156, China \\ 2 Department of Electrical Engineering, Nanjing University of Aeronautics and Astronautics, Nanjing 211106, \\ China; wanghaohao@nuaa.edu.cn \\ * Correspondence: hwj@e-mail.com or hwj@nuaa.edu.cn; Tel.: +86-025-87190042
}

Received: 11 August 2017; Accepted: 11 October 2017; Published: 14 October 2017

\begin{abstract}
Linear flux-switching permanent magnetic (LFSPM) machines are good choices for long stroke applications. These machines deliver high thrust force density in addition to the machine structure where permanent magnetics (PMs) and windings are all on the short mover. For LFSPM machines, their performance is always affected by big thrust force ripple. In this paper, for two C-core LFSPM machines of high thrust force capability, including a 6/13 C-core LFSPM (6/13LFSPM-C) machine and a sandwiched C-core LFSPM (SLFSPM-C) machine, and a thrust force ripple reduction method is proposed. The proposed method is developed by reducing the slot effect component of the cogging force based on staggered stator tooth, and suppressing the thrust force ripple caused by unbalanced three phase back-electromagnetic forces (EMFs) based on two end PMs. Based on finite element analysis (FEA) results, both C-core LFSPM machines can achieve small thrust force ripples as well as high sinusoidal back-EMFs, and at the same time, maintain high thrust force capability with the proposed method. It was also found that, the improved SLFSPM-C machine exhibited the same thrust force capability as the improved 6/13LFSPM-C machine, but with a much smaller thrust force ripple.
\end{abstract}

Keywords: linear machine; permanent magnet; flux-switching machine; thrust force ripple; cogging force

\section{Introduction}

Linear machines are capable of providing faster dynamic performance, higher precision, lower noise, lower maintenance, and lower pollution when compared with rotary machines as gear boxes, chains, and ball screws can be eliminated in linear motion, making these machines better choices in many industrial applications such as transportation, aerospace and other linear motion systems [1-3]. In recent years, linear flux-switching permanent magnet (LFSPM) machines, which inherit the advantages of high thrust density of the rotary flux-switching permanent magnetic (FSPM) machines, have attracted interest from researchers. For applications such as urban rail transit (URT) which always adopt linear machines with a long stator and short mover, the LFSPM machines, having the magnets and armature windings all on the mover, in addition to a simple and robust stator structure, are very suitable due to their high reliability, low expenses, and easy road maintenance $[4,5]$.

In many applications of linear machines, a high average thrust force is highly desirable, however, low thrust force ripples are also required. Due to the double salient structure of both the mover and stator, as well as the end effect, there exists considerable cogging forces in the LFSPM machines. These forces result in periodic ripples in thrust force, and consequently, worsen the performance of the LFSPM machines [6-8]. A method where assistant iron teeth are fixed on the mover 
ends to reduce the cogging force mainly caused by the end effect was presented in [8]. Based on this approach, optimization of the iron teeth was performed by [6] to reduce the cogging force. A C-core LFSPM machine with two new, multiple additional teeth was investigated by [9], where the cogging force can be reduced based on the optimization of these additional teeth. Several rotor-skewing methods to reduce cogging torque for rotary FSPM machines are also effective for the LFSPM to reduce the slot effect of the cogging force [10].

Therefore, in this paper, for two C-core LFSPM machines with high thrust force capability - the 6/13 mover/stator pole C-core LFSPM (6/13LFSPM-C) machine and the sandwiched C-core LFSPM (SLFSPM-C) machine-are tested for reducing their thrust force ripples in two steps. First, a staggered stator tooth structure is employed, designed to reduce the slot effect component of the cogging force for the two LFSPM machines without decreasing the magnitude of fundamental back-EMFs and the thrust force capability. Second, to reduce the thrust force ripple caused by unbalanced three phase back-EMFs, the magnitudes of the three phase back-EMFs of the two C-core LFSPM machines are balanced based on two end tip permanent magnets (PMs). This paper is organized as follows: In Section 2, the topologies of the two C-core LFSPM machines are introduced, and the thrust force capability of the two C-core LFSPM machines are compared. Next, Section 3 addresses the thrust ripple of the two machines, which is reduced in two steps by introducing a staggered stator tooth structure and an end PMs method. Finally, conclusions are given in Section 4.

\section{Machine Topology and Thrust Force Comparison}

\subsection{Machine Topology}

Topology of a conventional LFSPM machine is given in Figure 1a. The 6/13LFSPM-C machine can be developed from the conventional LFSPM machines by removing six mover poles and increasing the slot area. The 6/13LFSPM-C machine is found to have higher thrust density than the conventional LFSPM machine due to a larger slot area, as shown in Figure 1b [11].

Rotary sandwiched C-core flux switching permanent magnet machines, which can be developed from the conventional FSPM machines, are investigated in several papers, and have been verified to have better torque and power capabilities when compared with conventional structures [12]. The SLFSPM-C machine inherits the advantages of high power density from the rotary structure based on the same flux-switching concept, as shown in Figure 1c. The SLFSPM-C machine consists of six mover modules with two PMs of opposite polarity with a lamination segment sandwiched (sandwiched pole) between them in each mover pole. Additionally, the end assistant teeth are employed in the two machines to reduce the end effect component of the cogging force [8].

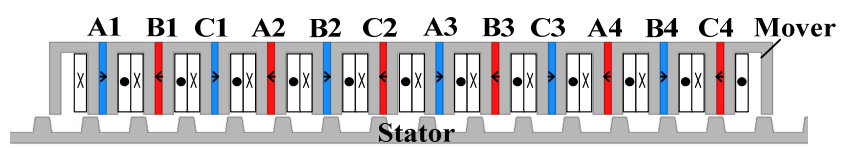

(a)

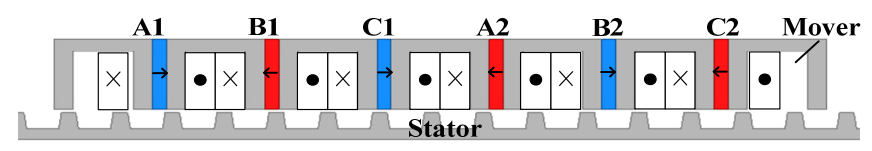

(b)

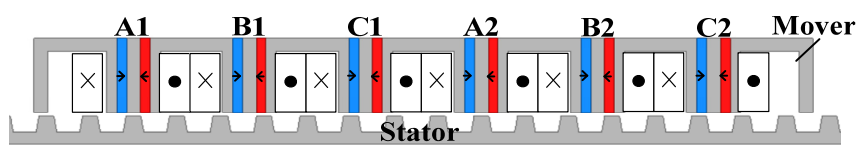

(c)

Figure 1. Linear flux-switching permanent magnetic (LFSPM) machines: (a) conventional LFSPM machine; (b) 6/13LFSPM-C machine; and (c) SLFSPM-C machine. 
For both C-core LFSPM machines, the open-circuit flux distribution at four mover positions are shown in Figures 2 and 3, where $\theta_{e}$ is the electrical degree of the mover position. As described in Figure 3, the SLFSPM-C machine utilizes the different polarity of two magnets to focus the flux through stator teeth, enhancing the usage of PMs [12].

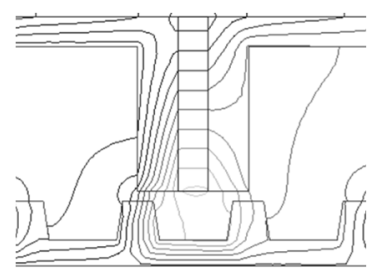

(a)

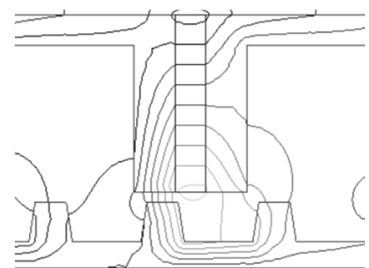

(b)

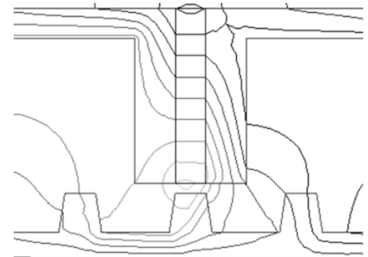

(c)

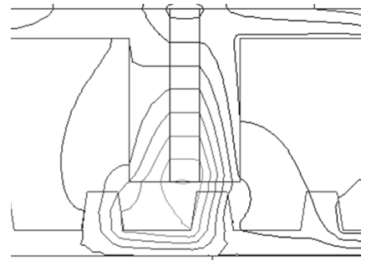

(d)

Figure 2. Open-circuit flux distribution of the 6/13 mover/stator pole C-core LFSPM (6/13LFSPM-C) machine at four mover positions: (a) $\theta_{e}=0^{\circ}$; (b) $\theta_{e}=90^{\circ}$; (c) $\theta_{e}=180^{\circ}$; (d) $\theta_{e}=270^{\circ}$.

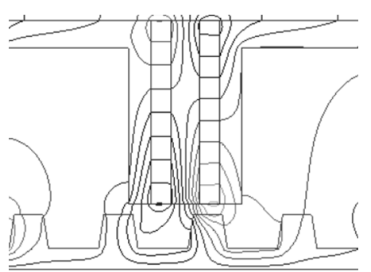

(a)

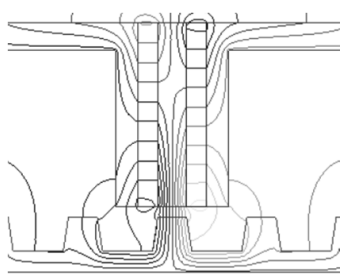

(b)

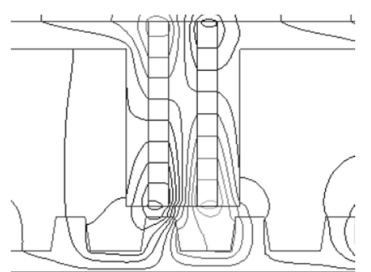

(c)

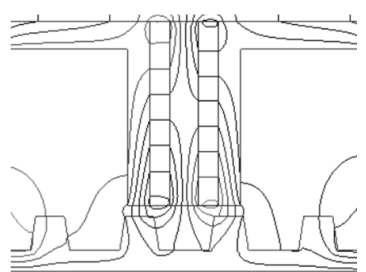

(d)

Figure 3. Open-circuit flux distribution of the sandwiched C-core LFSPM (SLFSPM-C) machine at four mover positions: (a) $\theta_{e}=0^{\circ}$; (b) $\theta_{e}=90^{\circ}$; (c) $\theta_{e}=180^{\circ}$; (d) $\theta_{e}=270^{\circ}$.

\subsection{Thrust Force Comparison}

Both C-core LFSPM machines are found to have better thrust and power capabilities when compared with the conventional structures [11,12], however, thrust force has not been previously compared between these two machines. In this section, the two C-core LFSPM machines are compared with an emphasis on the thrust force using finite element analysis (FEA) with ANSOFT Maxwell software 2D.

In this study, the dimensions and the optimized results of the parameters in [11] for the 6/13LFSPM-C machine are employed. Design parameters for the two LFSPM machines are shown in Figure 4, and major specifications are listed in Table 1, where the stator and mover specifications of the SLFSPM-C machine represent the original values. For a fair comparison, the SLFSPM-C machine was optimized for maximum average thrust force under fixed current density using the individual parameter optimization method [11]. As such, only one variable was altered, while others were kept constant under $I_{d}=0$ control. Next, this optimized variable was used to optimize a subsequent variable. Definitions of the optimization variables and the sequence for the SLFSPM-C machine are given in Table 2. Due to the slot area variation, the armature windings per phase are varied correspondingly to maintain fixed current density during the optimization. The optimized results of the SLFSPM-C machine are also given in Table 2.

After optimization of the SLFSPM-C machine, the two machines were compared. The back-EMFs of the two machines are given in Figure 5. Here, the results indicated that the three-phase no-load back-EMF magnitudes were unbalanced for both machines due to the unbalanced magnetic circuit in the end coil. 


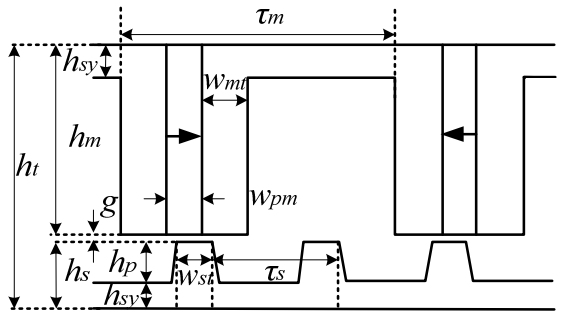

(a)

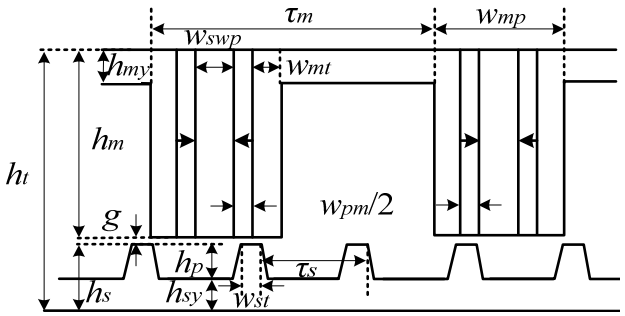

(b)

Figure 4. Design parameters: (a) 6/13LFSPM-C machine; (b) SLFSPM-C machine.

Table 1. Major specifications.

\begin{tabular}{|c|c|c|}
\hline Item and Symbol & 6/13LFSPM-C & SLFSPM-C \\
\hline Air gap length, $\mathrm{g}(\mathrm{mm})$ & \multicolumn{2}{|c|}{1} \\
\hline Total height, $h_{t}(\mathrm{~mm})$ & \multicolumn{2}{|c|}{25} \\
\hline Machine depth, $D$ (mm) & \multicolumn{2}{|c|}{100} \\
\hline Mover pole pith, $t_{m}(\mathrm{~mm})$ & \multicolumn{2}{|c|}{24} \\
\hline Stator pole height, $h_{p}(\mathrm{~mm})$ & \multicolumn{2}{|c|}{3.9} \\
\hline Stator pole width, $w_{s t}(\mathrm{~mm})$ & \multicolumn{2}{|c|}{3.1} \\
\hline Mover pole height, $h_{m}(\mathrm{~mm})$ & \multicolumn{2}{|c|}{17.5} \\
\hline Mover yoke thickness, $h_{m y}(\mathrm{~mm})$ & \multicolumn{2}{|c|}{3} \\
\hline Stator pole pith, $t_{s}(\mathrm{~mm})$ & 11.08 & 9 \\
\hline PM thickness, $w_{p m}(\mathrm{~mm})$ & 3 & 4 \\
\hline Mover tooth width, $w_{m t}(\mathrm{~mm})$ & 4.1 & 2.18 \\
\hline Mover sandwiched pole thickness, $w_{s w p}(\mathrm{~mm})$ & - & 2.84 \\
\hline Magnet remanence, $B_{r}(\mathrm{~T})$ & \multicolumn{2}{|c|}{1.2} \\
\hline Magnet relative permeability, $\mu_{r}$ & \multicolumn{2}{|c|}{1.034} \\
\hline Number of phases & \multicolumn{2}{|c|}{3} \\
\hline Armature windings per phase & \multicolumn{2}{|c|}{100 turns } \\
\hline Rated input current amplitude, (A) & \multicolumn{2}{|c|}{8} \\
\hline Rated velocity, $v(\mathrm{~m} / \mathrm{s})$ & \multicolumn{2}{|c|}{4} \\
\hline
\end{tabular}

Table 2. Optimization variables and results of the SLFSPM-C machine.

\begin{tabular}{ccc}
\hline Optimization Variables and Definition & Initial Value and Ranges & Results \\
\hline Split ratio, $A_{s}\left(h_{s} / h_{t}\right)$ & $0.26[0.2-0.3]$ & 0.28 \\
Stator pole width ratio, $w_{\text {st-ratio }}\left(w_{s t} / \tau_{s}\right)$ & $0.34[0.2-0.4]$ & 0.32 \\
Stator pole height ratio, $h_{p \text {-ratio }}\left(h_{p} / h_{s}\right)$ & $0.6[0.5-0.7]$ & 0.62 \\
Mover yoke thickness ratio, $h_{m y-\text {-ratio }}\left(h_{m y} / h_{m}\right)$ & $0.15[0.1-0.2]$ & 0.15 \\
Mover sandwiched pole ratio, $w_{\text {swp-ratio }}\left(w_{s w p} / w_{m t}\right)$ & $1.3[1-2]$ & 1.3 \\
Mover pole ratio, $w_{m p-\text { ratio }}\left(w_{m p} / \tau_{s}\right)$ & $1.24[1.2-1.3]$ & 1.27 \\
PM thickness, $w_{p m}$ & $4 \mathrm{~mm}[3 \mathrm{~mm}-5 \mathrm{~mm}]$ & $4 \mathrm{~mm}$ \\
\hline
\end{tabular}

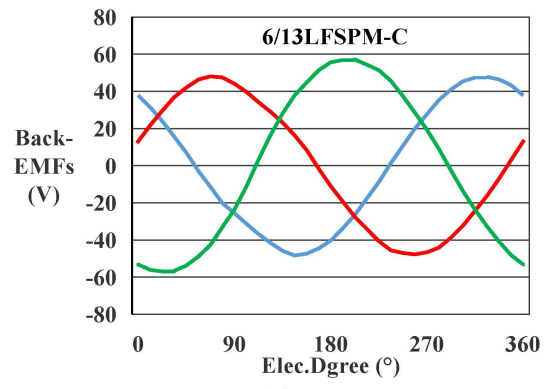

(a)

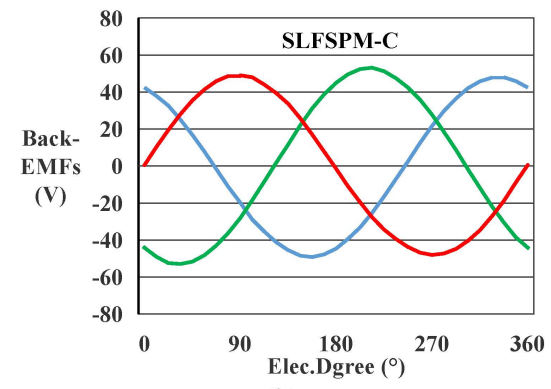

(b)

Figure 5. Three phase no-load back-EMFs: (a) 6/13LFSPM-C machine; (b) SLFSPM-C machine. 
Due to the same flux-switching concept as that of the conventional LFSPM machines, the output thrust force of the two C-core LFSPM machines under $d$ - $q$ axes can be expressed as [13]:

$$
F_{t}=\frac{3 \pi}{\tau_{s}}\left[\psi_{m} i_{q}+i_{d} i_{q}\left(L_{d}-L_{q}\right)\right]
$$

where $\psi_{m}$ is the fundamental magnitude of the PM flux-linkage, $i_{q}$ is the phase current in $q$-axis, $L_{d}$ and $L_{q}$ are the $d$-axis and $q$-axis inductances, respectively.

By using $I_{d}=0$ control method, that is, the three-phase currents are in phase with the back-EMF, the output thrust force under $d-q$ axes can be obtained as:

$$
F_{t}=\frac{3 \pi}{\tau_{s}} \psi_{m} I_{m}
$$

where $I_{m}$ is the fundamental magnitude of the phase current. It can be found that, the average thrust force is mathematically proportional to the fundamental magnitude of the PM flux-linkage under fixed phase current. That is, for the LFSPM machines, the thrust force is primarily due to the PMs.

The average thrust forces under different input current amplitudes are shown in Figure 6a. Likewise, the average thrust force under rated input current amplitude, for example $8 \mathrm{~A}$, is presented in Figure $6 \mathrm{~b}$. The results shown here indicate the thrust force of the two machines are almost equal.

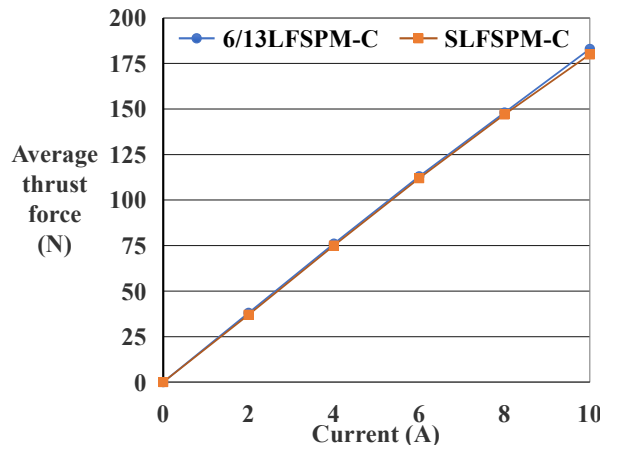

(a)

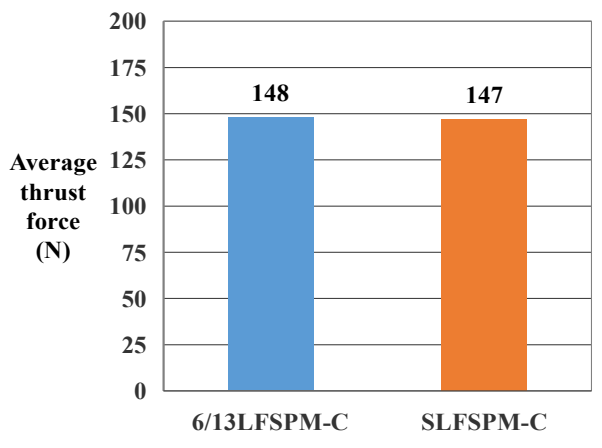

(b)

Figure 6. Average thrust force of the two machines: (a) under different input current amplitudes; (b) under rated input current amplitude, for example, $8 \mathrm{~A}$.

\section{Thrust Force Ripple Reduction}

There are three main reasons, based on machine structure, that will cause thrust force ripples in LFSPM machines: the cogging force, an unbalanced magnitude in three phase PM flux-linkage no-load back-EMFs, and harmonics in the PM flux-linkage. In this paper, end assistant teeth are already employed for the two machines to reduce the end effect component of the cogging force, as shown in Figure 1. As a result, the thrust force ripples of the two C-core LFSPM machines caused by this magnitude unbalance in three phase PM flux-linkage (no-load back-EMFs), the slot effect component of the cogging force and the harmonics in the PM flux-linkage (no-load back-EMFs) are reduced in two steps.

\subsection{Step 1, Reduction of the Cogging Force and Suppression of the Harmonics in No-Load Back-EMFs}

The double salient structure of the mover and stator causes a large slot effect component on the cogging force, resulting in the cogging forces of both machines being large, as seen in Figure 7.

To reduce the slot effect component of the cogging force, a staggered stator tooth structure is employed for both machines. Next, two machines with staggered stator tooth structure are proposed, namely, the 6/13LFSPM-C1 and SLFSPM-C1 machines. The topology of the 6/13LFSPM-C1 machine 
is given in Figure 8, for example, and while not shown, the SLFSPM-C1 machine has similar staggered stator tooth structure.

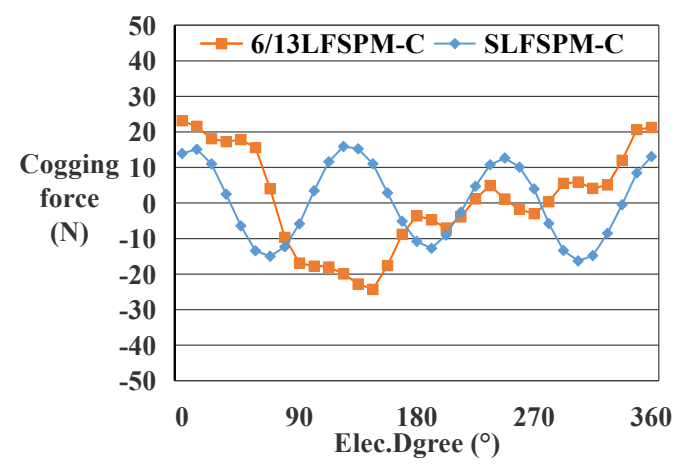

Figure 7. The cogging forces of the 6/13LFSPM-C machine and the SLFSPM-C machine.

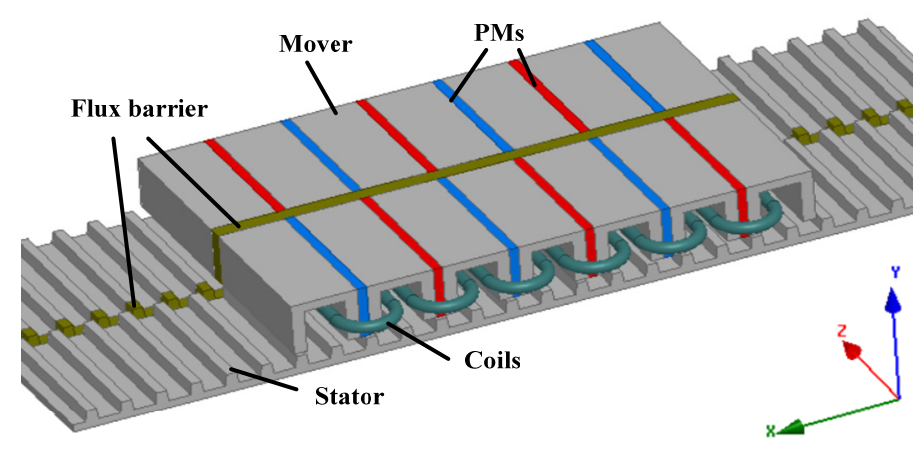

Figure 8. Structure of the 6/13LFSPM-C1 machine.

As demonstrated, the stator of the 6/13LFSPM-C1 machine is divided into two parts. The two parts are the same size, but are displaced in x-direction by staggered stator tooth. Correspondingly, the mover is also divided into two parts of the same size, with the magnets of two mover parts oppositely magnetized. One front mover pole and one back mover pole constitute one complete mover pole of the machine by sharing one armature coil. Additionally, to avoid a magnetic short circuit between the two mover parts, the two stator parts and the two mover parts are isolated by flux barriers at a depth of $5 \mathrm{~mm}$ for both machines.

Figure 9 demonstrates the open-circuit flux density of the mover part of the 6/13LFSPM-C1 machine (top view), indicating that employment of a flux barrier isolates the magnetic circuits of the two mover parts.

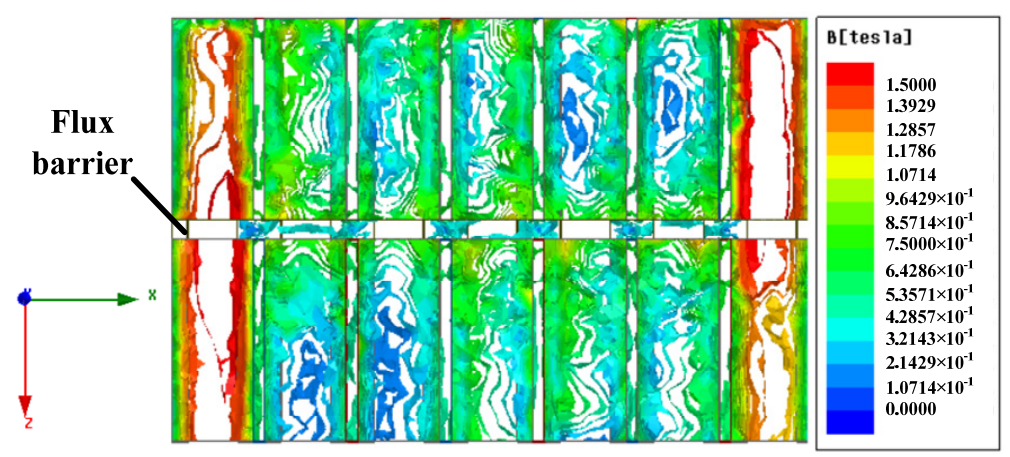

Figure 9. Open-circuit flux density of the mover of the 6/13LFSPM-C1 machine (top view). 
For both machines, the thrust force can be expressed as:

$$
F_{t}=F_{t 1}+F_{t 2}
$$

where $F_{t 1}$ and $F_{t 2}$ are the thrust forces of the two parts.

The cogging force for both machines can be expressed using the following Fourier series expansion:

$$
\begin{aligned}
F_{c o g} & =F_{c o g}+F_{c o g} 2 \\
& =F_{m 1} \sin \left(P \theta_{e}+\phi_{c 1}\right)+\sum F_{m n} \sin \left(n P \theta_{e}+\phi_{c n}\right)+F_{m 1} \sin \left(P \theta_{e}+\phi_{c 1}+P \theta_{s}\right)+\sum F_{m n} \sin \left(n P \theta_{e}+\phi_{c n}+n P \theta_{s}\right)
\end{aligned}
$$

where $F_{\operatorname{cog} 1}$ and $F_{\operatorname{cog} 2}$ are the cogging forces of the two parts, $F_{m 1}$ and $\phi_{c 1}$ are the fundamental magnitude and phase angle, respectively, $F_{m n}$ and $\phi_{c n}$ are the magnitude and phase angle of the $\mathrm{n}$-order harmonic component, respectively, $\theta_{e}$ is the electrical degree of the mover position, $P$ is the multiples of the cogging force period related to the machine electrical period, based on FEA results, for both machines $P=1$, and $\theta_{s}$ is the electrical degree of the displacement of the two stator parts.

Figure 10 demonstrates the peak-to-peak ( $p$-p) cogging force varying with the electrical degree of displacement of the two stator parts, $\theta_{s}$. The reference values for per-unit (PU) value are the p-p cogging force of the 6/13LFSPM-C machine, and the SLFSPM-C machine, respectively, that is, $\theta_{s}=0^{\circ}$, which are also the maximum p-p cogging forces. For both machines, the p-p cogging forces reach their minimum value when $\theta_{S}=180^{\circ}$. This value is less than $40 \%$ and $15 \%$ of the maximum p-p cogging forces for the 6/13LFSPM-C1 machine and the SLFSPM-C1 machine, respectively. Additionally, when $\theta_{s}=146.25^{\circ}$ and $\theta_{s}=213.75^{\circ}$ for the $6 / 13$ LFSPM-C 1 machine, and $\theta_{s}=56.25^{\circ}$ and $\theta_{s}=303.75^{\circ}$ for the SLFSPM-C1 machine, the p-p cogging force can reach its second smallest value.

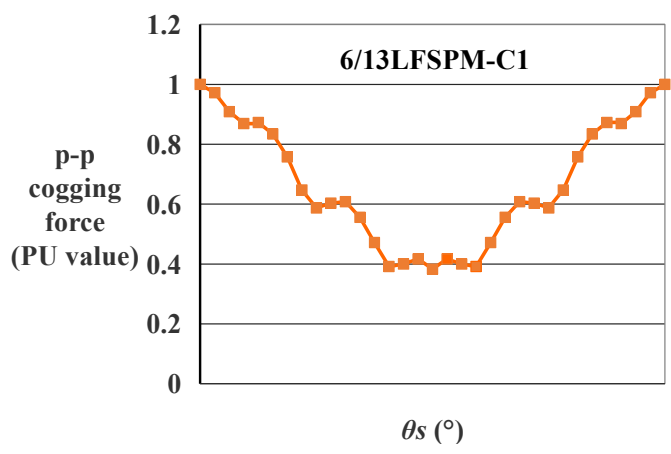

(a)

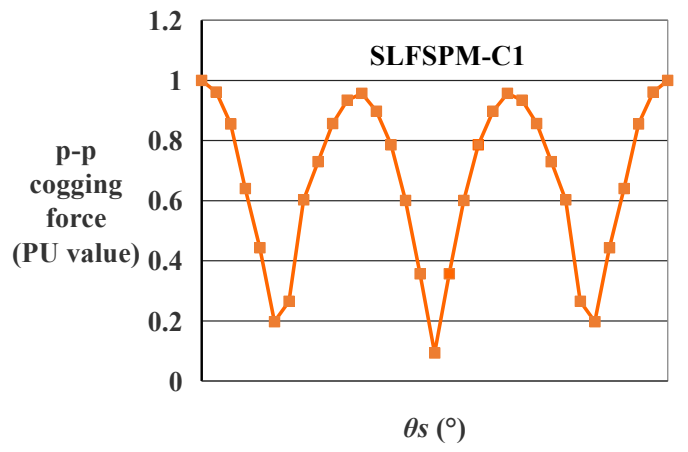

(b)

Figure 10. The variation of the peak-to-peak (p-p) cogging force with $\theta_{s}$ : (a) 6/13LFSPM-C1 machine; (b) SLFSPM-C1 machine.

The chosen value of $\theta_{s}$ depends not only on the reduction of cogging force, but the influence of the no-load back-EMF must be considered as well. As such, the no-load back-EMF based on staggered stator tooth is analyzed as follows.

As outlined in Figure 8, the magnets of the two mover parts are oppositely magnetized, with a front and a back mover pole constituting one mover pole by sharing one armature coils. Thus, the no-load back-EMF of one armature coil, for example, coil A1 can be expressed as:

$$
E_{A 1}=E_{A 11}-E_{A 12}
$$

where $E_{A 11}$ and $E_{A 12}$ are the no-load back-EMFs, induced by the PM flux-linkages of the corresponding front and back mover pole, respectively. 
By considering the second-order harmonic component, Equation (5) can be expressed as:

$$
\begin{aligned}
E_{A 1} & =E_{A 11}-E_{A 12} \\
& =\left[E_{m} \sin \left(\theta_{e}+\phi_{1}\right)+E_{m 2} \sin \left(2 \theta_{e}+\phi_{2}\right)\right]-\left[E_{m} \sin \left(\theta_{e}+\phi_{1}+\theta_{s}\right)+E_{m 2} \sin \left(2 \theta_{e}+\phi_{2}+2 \theta_{s}\right)\right] \\
& =-2 E_{m} \sin \frac{\theta_{s}}{2} \cos \left(\theta_{e}+\phi_{1}+\frac{\theta_{s}}{2}\right)-2 E_{m 2} \sin \theta_{s} \cos \left(2 \theta_{e}+\phi_{2}+\theta_{s}\right)
\end{aligned}
$$

where $E_{m}$ and $\phi_{1}$ are the fundamental magnitude and the phase angle, respectively, $E_{m 2}$ and $\phi_{2}$ are the magnitude and phase angle of second-order harmonic component, respectively.

From Equation (5), the fundamental magnitude can reach its maximum value when $\theta_{s}=180^{\circ}$. At this angle, the magnitude of the second-order harmonic component is zero, indicating that the no-load back-EMFs, $E_{A 11}$ and $E_{A 12}$, are complementary, and the second-order harmonic of $E_{A 1}$ is eliminated without fundamental magnitude decrease. For other angles such as $\theta_{S}=146.25^{\circ}$ and $\theta_{s}=213.75^{\circ}$ for the $6 / 13 \mathrm{LFSPM}-\mathrm{C} 1$ machine, and $\theta_{s}=56.25^{\circ}$ and $\theta_{s}=303.75^{\circ}$ for the SLFSPM-C1 machine, the fundamental magnitude of the back-EMF will be reduced and, as a result, the thrust force capability will be decreased. Therefore, when $\theta_{s}=180^{\circ}$, the two stator segments are displaced by half a pole-pitch, $\tau_{s} / 2$, and the two machines can achieve minimum cogging force and high sinusoidal back-EMFs without a magnitude decrease. Thus, $\tau_{s} / 2$ is chosen for the two C-core LFSPM machines with staggered stator tooth.

The cogging force, the average thrust force under rated current, and the proportion of $\mathrm{p}$-p cogging force to the average thrust force of the C-core LFSPM machines are given in Figure 11. A comparison of Figure 7 with Figure 11 shows that for both machines with staggered stator teeth, the p-p cogging forces are significantly suppressed. Specifically, with the SLFSPM-C1 machine, the p-p cogging force is very low with $2 \%$ of the average thrust force under rated current.

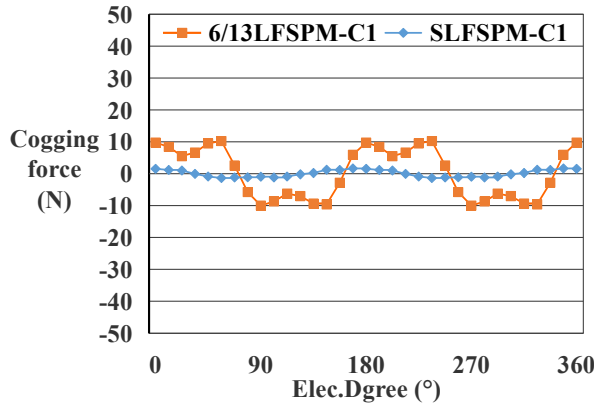

(a)

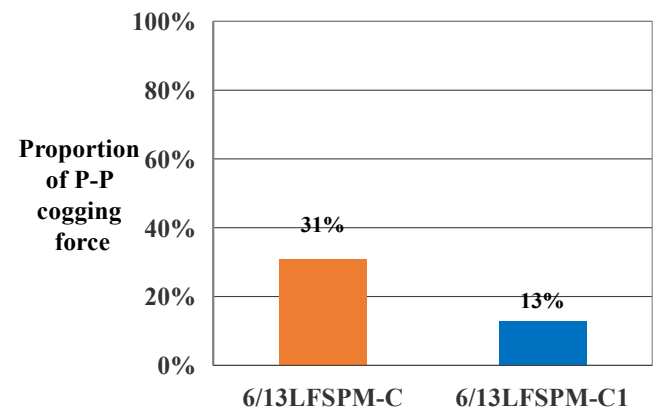

(c)

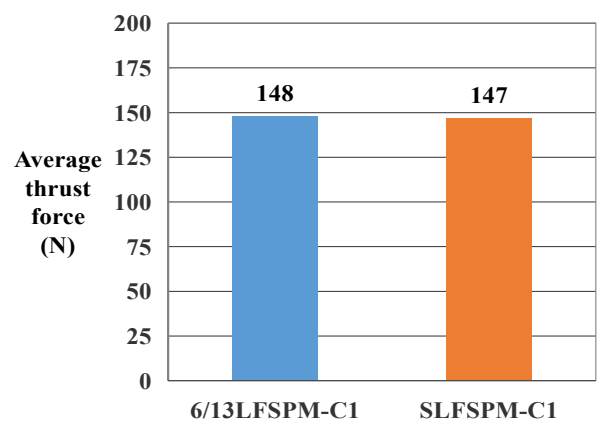

(b)

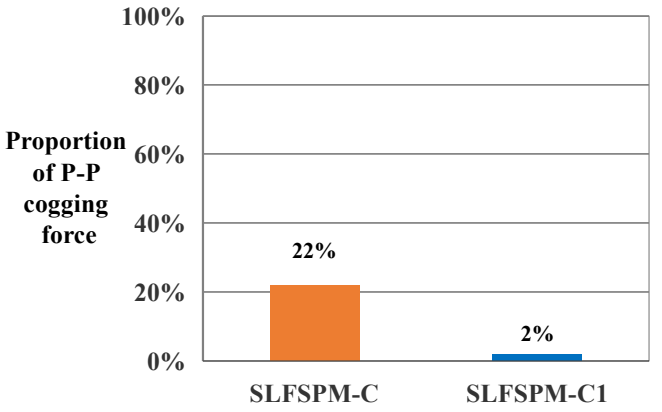

(d)

Figure 11. Cogging force of the C-core LFSPM machines: (a) cogging force waveform; (b) average thrust force; (c) the proportion of p-p cogging force to average thrust force of the C-core 6/13LFSPM machines; and (d) the proportion of p-p cogging force to average thrust force of the C-core SLFSPM machines.

The harmonics distribution and the calculated total harmonic distortion (THD) of the phase no-load back-EMF of the two C-core LFSPM machines are given in Figure 12. Figure 12 shows that in both machines, with staggered stator tooth, even order harmonics in the phase back-EMF are 
eliminated without decreasing the fundamental magnitude, as well as an obvious reduction in the THDs. This reduction indicates that the thrust force ripples caused by the harmonics will be suppressed. Additionally, the phase no-load back-EMF of the SLFSPM-C1 machine is nearly sinusoidal, and the THD is only $0.5 \%$.

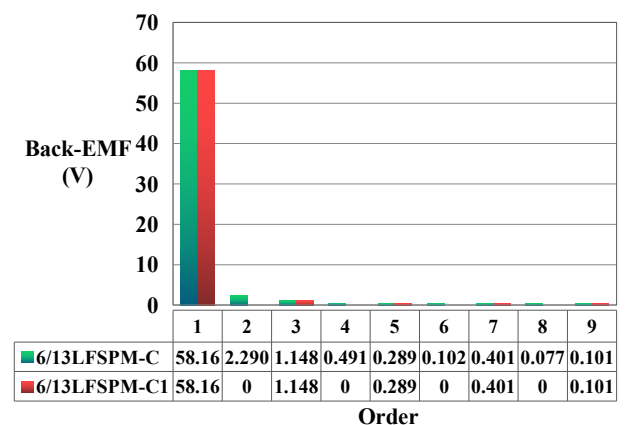

(a)

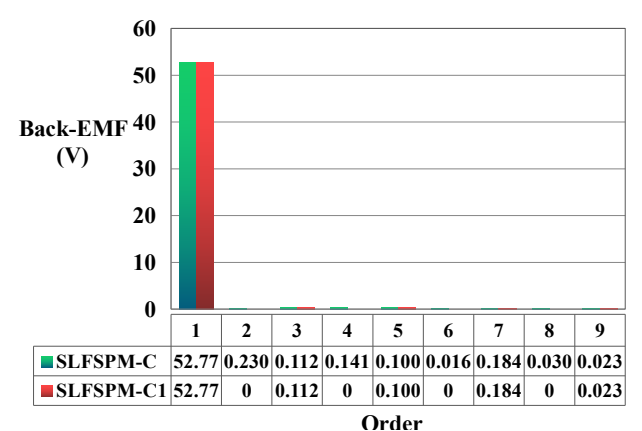

(c)

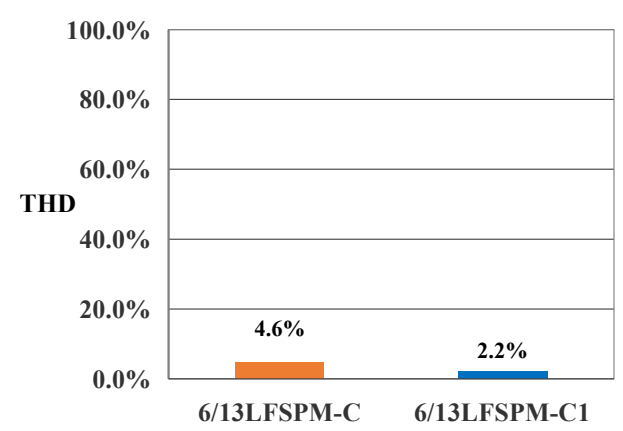

(b)

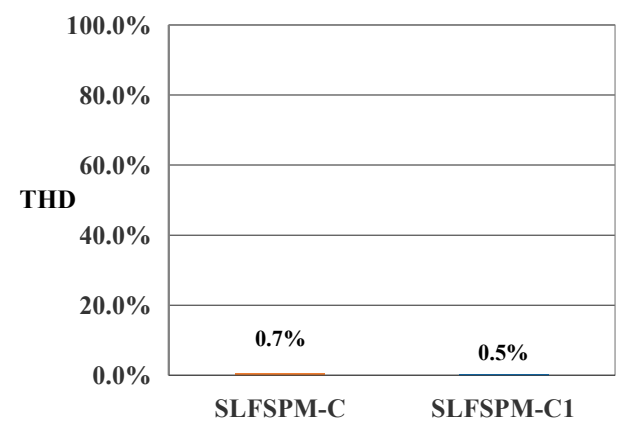

(d)

Figure 12. Back-EMFs of the C-core LFSPM machines: (a) harmonics distribution of the C-core 6/13LFSPM machines; (b) total harmonic distortions (THDs) of the C-core 6/13LFSPM machines; (c) harmonics distribution of the C-core SLFSPM machines; and, (d) THDs of the C-core SLFSPM machines.

Analysis shows that by employing the staggered stator tooth structure for both C-core LFSPM machines, the slot components of the cogging force are reduced to their minimums without thrust force capability decrease. In rotating machines, skewing methods are widely used to prevent the slot effect component of the cogging torque. A general step skewing method, arranging the rotor axially in discrete steps, is investigated in [10], and is verified to be effective in reducing the cogging torque for rotating FSPM machines. Based on the step skewing method in [10], the stator step skewing structure is employed for the SLFSPM-C machine for comparison.

Since the step skewing number should be small to simplify the implementation, a stator three step skewing structure is used in this study. The stator structure of the SLFSPM-C machine with stator three step skewing structure (SLFSPM-CS) is shown in Figure 13a. Based on FEA results, the variation of the average thrust force under rated current and the proportion of $\mathrm{p}-\mathrm{p}$ cogging force to the average thrust force with skewing step displacement $\left(D_{s}\right)$ of the SLFSPM-CS machine are given in Figure 13b, where $\tau_{s}$ is the stator pole pitch. The results show that when the skewing step displacement is $\tau_{s} / 9$, that is, $1 \mathrm{~mm}$, the SLFSPM-CS machine has the smallest proportion of p-p cogging force to average thrust force, at about $11 \%$, however, the average thrust force is decreased from $147 \mathrm{~N}$ to $116 \mathrm{~N}$. The results of the step skewing method using in the SLFSPM machine are similar to using in the rotating machines, that is, the skewing method always reduces the cogging force (torque) with the thrust force (torque) decrease.

When comparing Figure 11 with Figure 13b, the cogging force of the SLFSPM-C machine can be reduced from $22 \%$ to $2 \%$ without thrust force decrease by employing the staggered stator tooth structure, and be reduced from $22 \%$ to $11 \%$ with a $21 \%$ decrease in thrust force. 


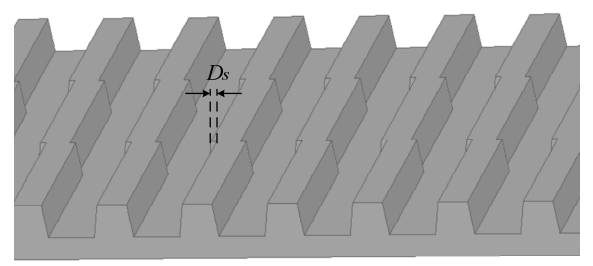

(a)

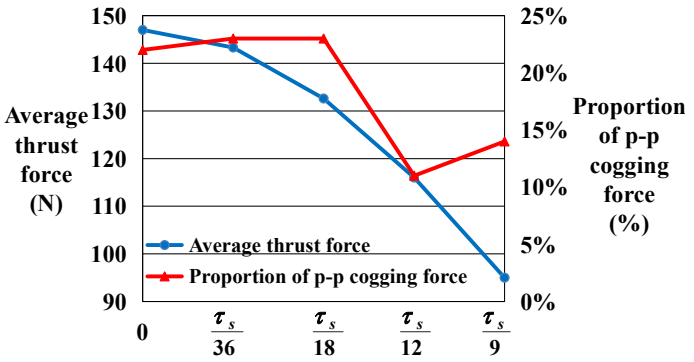

(b)

Figure 13. The SLFSPM-CS machine showing (a) the stator structure; (b) the variation of average thrust force under rated current and proportion of $\mathrm{p}-\mathrm{p}$ cogging force to the average thrust force with skewing step displacement.

\subsection{Step II: The Balance of the Three Phase No-Load Back-EMFs}

Although the end assistant teeth are used for the two machines, the unbalanced magnetic circuit in the end coil still exists, as shown in Figure 5. The amplitudes of the three phase no-load back-EMFs for both of the machines are not equal. The back-EMF amplitudes of the end coil are smaller than that of the mid coil, which will decrease the thrust force capability and increase the thrust force ripple. Therefore, in order to suppress the end effect for the end coil, a simple method to respectively add two end PMs to both ends of the machine can be used. The two machines with the end PMs are identified as the 6/13LFSPM-C2 machine, and the SLFSPM-C2 machine, respectively. Figure 14 shows a cross section of the 6/13LFSPM-C1 machine as an example. In order to obtain balanced magnitudes of three phase no-load back-EMFs, the thickness of the end PMs, $w_{p m s}$, is optimized in the range of $1-5 \mathrm{~mm}$ using FEA, with the final optimized values of $4 \mathrm{~mm}$ for the 6/13LFSPM-C2 machine, and $3.8 \mathrm{~mm}$ for the SLFSPM-C2 machine, respectively. Figure 15 shows the no-load back-EMFs with optimized end PMs, where the magnitudes of three phase back-EMF are almost equal or balanced.

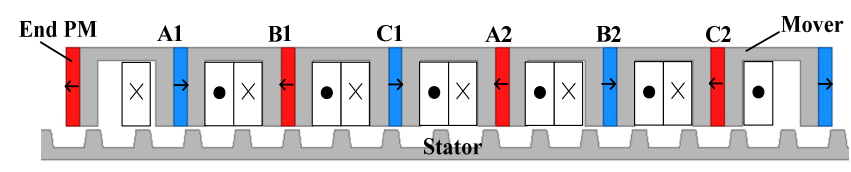

Figure 14. The cross section of the machine with end PMs using the 6/13LFSPM-C2 machine as an example.

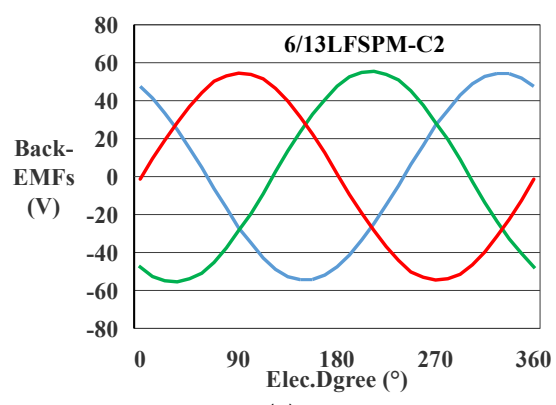

(a)

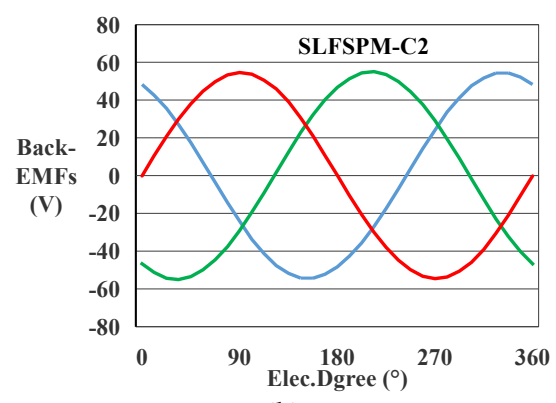

(b)

Figure 15. Three phase no-load back-EMFs with end PMs: (a) 6/13LFSPM-C2 machine; (b) SLFSPM-C2 machine.

\subsection{The Results of the Thrust Force Ripple Reduction}

Regarding thrust force, including thrust forces, average values, and the proportion of $\mathrm{p}-\mathrm{p}$ thrust force ripple to average thrust force are given in Figures 16-18. From the results shown in Figure 16, 
the end PMs can not only balance the three phase back-EMFs, but also enhance the thrust force capability. The thrust forces under the end PMs are about 9.5\% higher for the 6/13LFSPM-C2 machine, and 10.2\% higher for the SLFSPM-C2 machine than these without end PMs. Additionally, in Figures 16 and 18, based on the reduction of the cogging force and balancing the three phase back-EMFs, the thrust force ripples of the two C-core machines can be greatly suppressed. Specifically, the thrust force ripple is reduced to $6 \%$ of the average thrust force for the SLFSPM-C2 machine.

However, due to the flux barrier depth of $5 \mathrm{~mm}$ in the two machines with staggered stator tooth, as shown in Figure 8, the total volume is about 5\% larger than that of the original machine, thus, the thrust force density is slightly decreased.

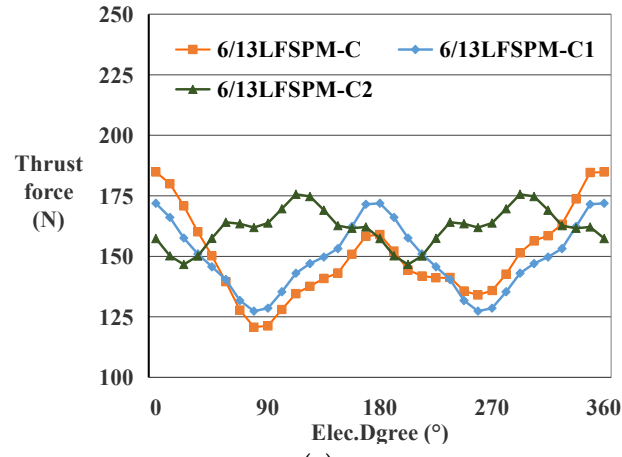

(a)

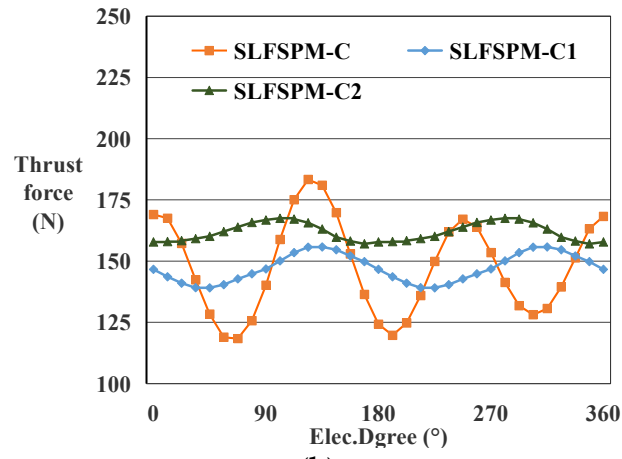

(b)

Figure 16. The thrust forces of the two C-core machines before and after the two steps: (a) C-core 6/13LFSPM machines; (b) C-core SLFSPM machines.

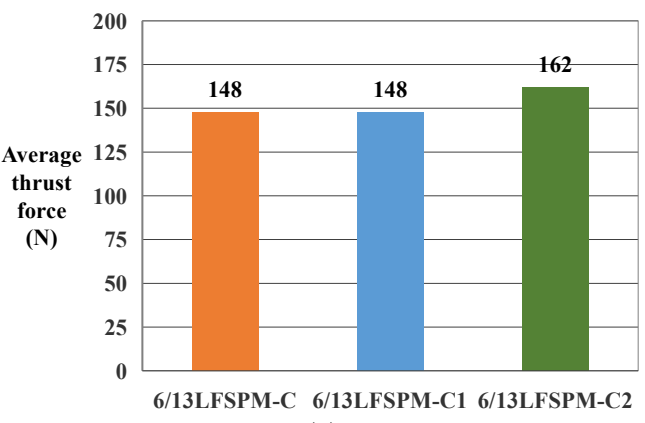

(a)

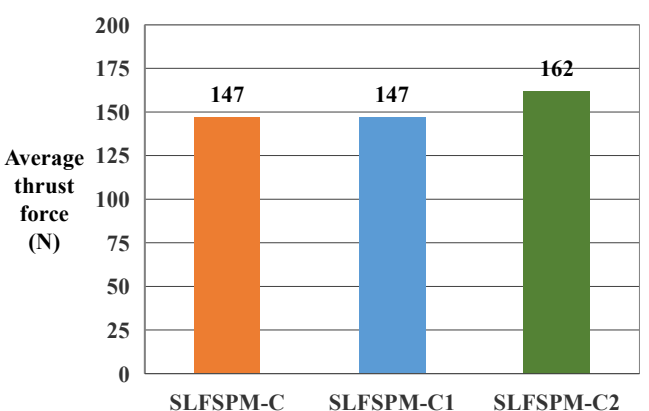

(b)

Figure 17. The average thrust forces of the two C-core machines before and after the two steps: (a) 6/13LFSPM machines; (b) C-core SLFSPM machines.

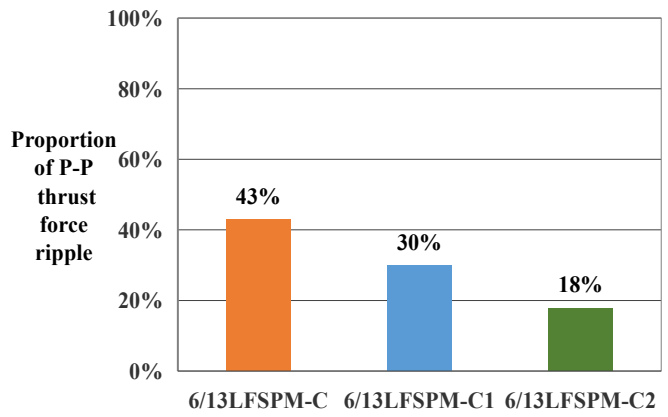

(a)

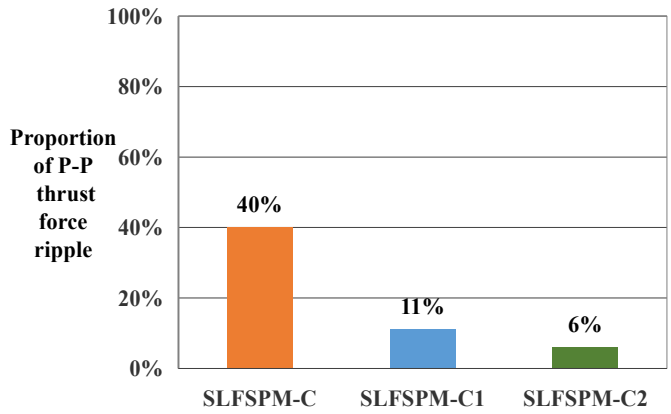

(b)

Figure 18. The proportion of $p-p$ thrust force ripple to the average thrust force of the two C-core machines before and after the two steps: (a) C-core 6/13LFSPM machines; (b) C-core SLFSPM machines. 


\section{Conclusions}

The thrust force ripple always affects the performances of the LFSPM machines. The proposed method in this paper to suppress the thrust force ripple for two C-core LFSPM machines of high thrust force capability is effective and practical.

The following conclusions can be obtained:

(1) Based on the staggered stator tooth and the design of the displacement of the two stator parts, these C-core machines can reduce cogging force to a minimum and achieve high sinusoidal back-EMFs without a decrease in thrust force capability.

(2) Based on the assistant of end PMs, for the two C-core machines, the magnitude of three phase no-load back-EMFs can be balanced, and in turn, the thrust force capability can be further enhanced, in addition to the reduction of thrust ripples brought by unbalanced back-EMFs.

(3) The 6/13LFSPM-C2 machine and the SLFSPM-C2 machine have the same thrust force capability, however, the SLFSPM-C2 machine exhibits a very low thrust force ripple, which is far smaller than that of the 6/13LFSPM-C2 machine.

(4) The proposed thrust force ripple reduction method, based on two steps, is general, practical, and can be employed for conventional LFSPM machines to suppress thrust ripples.

Therefore, based on the above conclusions, the SLFSPM-C2 machine is more suitable for applications that require high thrust force and low thrust ripple, exhibiting great potential for many applications, such as urban rail transit.

Acknowledgments: This work was supported by National Natural Science Foundation of China (51407090, 51741705), Natural Science Foundation of Jiangsu Province (BK20140815) and Central University Basic Research Funds (NJ20160043).

Author Contributions: Wenjuan Hao is the main author of this manuscript who conceived the ideas and performed the analysis. Yu Wang provided important guidance and gave some useful suggestions in the construction of this paper. All the authors have contributed significantly to this work.

Conflicts of Interest: The authors declare no conflict of interest.

\section{References}

1. Du, Y.; Jin, N. Research on characteristics of single-sided linear induction motors for urban transit. In Proceedings of the 2009 IEEE International Conference on Electrical Machines and Systems (ICEMS), Tokyo, Japan, 15-18 November 2009; pp. 1-4.

2. Stumberger, G.; Zarko, D.; Aydemir, M.T.; Lipo, T.A. Design and comparison of linear synchronous motor and linear induction motor for electromagnetic aircraft launch system. In Proceedings of the 2003 IEEE Electrical Machines and Systems Electric Machines and Drives Conference (IEMDC), Madison, WI, USA, 1-4 June 2003; pp. 494-500.

3. Kim, Y.K.; Gu, B.G.; Jung, I.S.; Won, S.H.; Hur, J. Analysis and Design of Slotted Tubular Linear Actuator for the Eco-pedal System of a Vehicle. IEEE Trans. Magn. 2012, 48, 939-942. [CrossRef]

4. Zhu, Z.Q.; Chen, X.; Chen, J.T.; Howe, D.; Dai, J.S. Novel linear flux-switching permanent magnet machines. In Proceedings of the 2008 IEEE International Conference on Electrical Machines and Systems (ICEMS), Wuhan, China, 17-20 October 2008; pp. 2948-2953.

5. Gandhi, A.; Parsa, L. Thrust Optimization of a Flux-Switching Linear Synchronous Machine with Yokeless Translator. IEEE Trans. Magn. 2013, 49, 1436-1443. [CrossRef]

6. Min, W.; Chen, J.T.; Zhu, Z.Q.; Zhu, Y.; Duan, G.H. Optimization of linear flux switching permanent magnet motor. In Proceedings of the 2010 IEEE Vehicle Power and Propulsion Conference (VPPC), Lille, France, 1-3 September 2010; pp. 1-6.

7. Zhou, S.G.; Yu, H.T.; Hu, M.Q.; Jiang, C.X.; Hao, L. Reduction of Cogging Force in a Linear Flux-Switching Permanent-Magnet Brushless AC Machine for Direct-Drive Applications. IEEE Trans. Magn. 2011, 47, 3252-3255. [CrossRef]

8. Wang, C.F.; Shen, J.X.; Wang, Y. A New Method for Reduction of Detent Force in Permanent Magnet Flux-Switching Linear Motors. IEEE Trans. Magn. 2009, 45, 2843-2846. [CrossRef] 
9. Du, Y.; Yang, G.; Quan, L.; Zhu, X.Y.; Xiao, F.; Wu, H.Y. Detent Force Reduction of a C-core Linear Flux-Switching Permanent Magnet Machine with Multiple Additional Teeth. Energies 2017, 10, 318. [CrossRef]

10. Fei, W.; Luk, P.C.K.; Shen, J. Torque Analysis of Permanent Magnet Flux Switching Machines with Rotor Step Skewing. IEEE Trans. Magn. 2012, 48, 2664-2673. [CrossRef]

11. Min, W.; Chen, J.T.; Zhu, Z.Q.; Zhu, Y.; Zhang, M. Optimization and Comparison of Novel E-core and C-core Linear Switched Flux PM Machines. IEEE Trans. Magn. 2011, 47, 2134-2141. [CrossRef]

12. Zhu, Z.Q.; Zhou, Y.J. Torque Density and Magnet Usage Efficiency Enhancement of Sandwiched Switched Flux Permanent Magnet Machines Using V-Shaped Magnets. IEEE Trans. Magn. 2013, 49, 3834-3837. [CrossRef]

13. Cao, R.W.; Cheng, M.; Hua, W.; Wang, X.; Zhao, W.X. Modeling of a Complementary and Modular Linear Flux-Switching Permanent Magnet Motor for Urban Rail Transit. IEEE Trans. Energy Convers. 2012, 27, 489-497. [CrossRef]

(C) 2017 by the authors. Licensee MDPI, Basel, Switzerland. This article is an open access article distributed under the terms and conditions of the Creative Commons Attribution (CC BY) license (http://creativecommons.org/licenses/by/4.0/). 